\title{
sciendo
}

DOI 10.2478/sbe-2020-0032

SBE no. 15(2) 2020

\section{RURAL DEVELOPMENT IN ROMANIA - A FEW CONSIDERATIONS}

\author{
LUCIAN PAUL \\ Lucian Blaga Univeristy of Sibiu, Romania
}

\begin{abstract}
:
The 'Agenda 2000' introduces the Rural Development Policy, as part of the Common Agricultural Policy (CAP), as a complex policy that can ensure a stable income and a reasonable standard of living for the rural population. Rural development is a major CAP objective since over $50 \%$ of the population lives in rural areas and accounts for $80 \%$ of E.U. Territories. As a concept, the 'rural area' is defined both at a national and European level following specific criteria; however, these criteria differ from one country to another. A complete definition can be found in the European Charter of Rural Areas. Between 2014-2020, the development of rural areas in Romania is supported by the National Rural Development Program. It provides non-reimbursable funds from the European Union and funding from the Government of Romania. Convergence with the Europe 2020 Strategy is ensured through the Partnership Agreement with the European Union, which covers a number of challenges and thematic objectives. In order to achieve them, well-founded investment programs are needed. These programs must have a direct impact on increasing the living standards of the population residing within rural areas. Over 19 billion euros were allocated to Romania for the 2014-2020 period; these funds were used for agricultural policy and rural development. The total budget of the NRDP (2014-2020) is 9.4 billion euros, of which 1.3 billion euros comes from national funding. We believe the achievements recorded in rural areas, up to 2020, are modest and do not reflect the proposed objectives. Thus, projects were drawn up at national and local levels seldom support rural development and do not reflect development needs; sadly, these projects are often drawn up without focusing on efficiency.
\end{abstract}

Key words: rural development, rural infrastructure, durable growth, competitive increase, labor force migration

\section{Introduction}

Rural areas occupy some $50 \%$ of E.U. territories, and include a population of 113 million, providing $20 \%$ of employment and $15 \%$ of the gross added value of the European economy. $45 \%$ of the Romanian population lives in rural areas, and $55 \%$ in urban areas. At a European level, Romania is considered the most rural country, given the permanent migration of the population, not only towards urban areas but also towards other countries. 
In the vast majority of rural areas, half of the labor force works only in agriculture, with per capita GDP accounting for less than $50 \%$ of the EU average.

When it comes to these rural areas, Romania faces great challenges in helping these regions reach their economic and social potential in sectors like the food industry or forestry. Rural development is the subject of extensive and diversified social and economic programs that support sustainable development in rural areas.

Through the programs and funds it provides, the E.U. aims to encourage the economic and social development of rural areas. Romania's rural economy lacks diversification and relies almost exclusively on farming. E.U. funding for rural areas is poorly managed. The European support for these rural areas did not actually support investment, but rather farmers' production and income. At present, agriculture practiced in the rural areas in Romania still lacks high-performance equipment, storage spaces for primary production, but also means of packaging and means of transporting the products all the way to the market.

Villages in rural areas evolve differently. For example, there are many small villages, where the population is all but gone, and those living there are exposed to poverty and social exclusion; however, there are also well-developed villages, close to bigger towns, who have an adequate transport infrastructure, as well as business opportunities.

The NRDP doesn't just support agricultural activities, but also investments into other areas, like tourism, food industry, and craftsmanship.

\section{The concept of rural development}

A rural area includes territories and communities, natural landscapes, agricultural fields, forests, habitats, and traditional cultures. (Rusali, 2013)

In Europe, a "rural area" is defined differently from one country to another, based on the following elements: the size of the community, the way in which the fields are used, economic and cultural activities, or specific facilities.

The "modern rural area" is the result of a complex process of both continuity, and discontinuity that started decades ago and continues to this day. New lifestyle models replace traditional ones, and the modernization of villages and rural societies means the transformation of all the elements of this social space (Popescu, Popescu, Per \& Csosz, 2018). The European Charter of Rural Areas refers to the way in which a territory is designed and defines the spatial expression of ecological, cultural, social, and economic policies.

The Charter also clarifies "rural areas" as being "distinct entities" as compared to urban areas, by delimiting an internal area that includes small villages and towns, in which a large part of all available terrain is used for agriculture, aquaculture and fishing. Economic and cultural activities in these areas are an integral part of the "rural area" defined by the Charter.

The term "rural area" is frequently used in politics and economics, but there is no unified definition for it. The rural area "forms a diverse and complicated economic structure" that includes villages, but also small towns, forests, small trading activities, 
tourism, other small companies, craftsmanship workshops, small and medium industry, natural landscapes, and cultural traditions. (Baum \& Weingarten, 2004).

As agricultural activities decrease in importance, and more and more population gets additional income from other sources, there are more and more differences between different rural areas, in the last decades. (Baum \& Weingarten, 2004)

In 1994, the OECD issued a simple definition of the "rural area", with the purpose of it being used internationally. The only criterion was population density. If it was below 150 inhabitants/sq $\mathrm{km}$, then that community was a rural one.

Regarding the "rural area", there are further differences between the rural area and agricultural area. Although somewhat similar, the "rural area" is more inclusive, as it includes the latter as well.

European rural areas include diverse territories and fulfill different functions. (Gallaro-Cobos, 2010). This diversity includes physical and morphological characteristics, biodiversity, landscapes, as well as social characteristics, like the way in which the land is used, culture, traditions, symbolism, while also considering it a priority to maintain the standardization of the development model.

Another concept one encounters when researching "rural areas" is that of "disadvantaged rural areas". These areas are characterized by low-income households, people with low levels of education and skills, and lack of basic infrastructure, running water, and electricity. In these rural areas, poverty is often extreme and is generally passed down from one generation to the next. Chronic poverty in marginalized rural areas is caused by the underdevelopment of infrastructure (no roads, no water, no sewerage), lack of health services, education, and culture.

According to E.U. law, national authorities have the task of establishing criteria for the delimitation of disadvantaged rural areas and therefore have a responsibility in selecting these regions, with the purpose of supporting and promoting them. At the moment, the categories and criteria for the delimitation of less-favored areas can be found in Regulation No. 1305/2013 of the European Parliament and of the Council Notes of 17 December 2013 regarding the support for rural development by the European Agricultural Fund for Rural Development (EAFRD).

There are 3 types of disadvantaged regions (Dax \& Machold, 2007): mountainous areas, where the altitude and slopes diminish the possibility of mechanization, other disadvantaged rural areas, that are characterized by lands with low productivity, enterprises with below-average economic results, low agricultural incomes, low population density and the tendency of a sustained exodus of the population, and areas characterized by specific disadvantages, such as unfavorable natural conditions (for example, swamps, etc.).

The main characteristics of rural areas. According to Steiner (2003) are low population density, special social and economic structures, and livelihoods, reliance on agriculture, low incomes, difficult accessibility, proximity to borders, lack of advantages arising from congestion.

According to Otiman (1997). rural development, at a national and regional level, should include the rural area's functions, namely: it's economic, ecologic, social, and cultural functions. 
Regarding the concept of rural development, Moseley (2003) formulated the following three definitions:

- an extended one that includes all issues related to the collective vitality of people and places in rural areas, including education, health, public services and facilities, leadership, governance, and cultural heritage, as well as general and specific economic issues;

- a multidimensional process that aims to integrate economic, social, cultural and environmental objectives, in a sustainable manner;

- a sustained and sustainable process of economic, social, cultural, and environmental change, carried out in order to determine the long-term well-being of the entire community.

Rural development policy must also contribute to achieving the goals of sustainable development in terms of increasing competitiveness and improving the environment in rural areas. while increasing the quality of life in these areas.

\section{The evolution of rural development in Romania}

Rural development is a component of territorial development. The asymmetry is due to the fact that until 1990, industrial development determined the development of cities to the detriment of rural areas. Much of the rural population worked in factories quite far from their residence. With the collectivization of agriculture and the massive industrialization of the economy, the activities and customs of Romanian villages have undergone profound transformations, determined by the lack of land ownership.

After the events of 1989, rural areas experienced a new stage in evolution, due to the return of the population to rural areas as a result of land dispossession. This population practices subsistence farming on small and very small plots, often without any agricultural equipment. In order to support traditional agriculture, at least one tractor was needed, and it was to be paid in installments by the farmer, from the income obtained from cultivating the land. Unfortunately, the restitution of these lands also determined their excessive disintegration, which led to their transformation into small and medium farms, with low productivity. Thus, subsistence agriculture was widely practiced, with an increase of the population employed in agriculture, obtaining primary agricultural products in rather small quantities.

We believe it is necessary to merge small and medium-sized lands into modern farms with an average size of 30 hectares. These farms should have appropriate mechanization, with activities that increase productivity and create jobs in rural areas. The productivity of agricultural activities in rural areas is 5 times lower than the national average and 1.5 times lower than productivity in the industrial and construction sectors.

A characteristic of the average, Romanian rural area is demographic decline, the decrease of the rural population due to aging, but also due to the exodus of this population towards areas with better-paid jobs. The main factors of this decline are the negative natural growth of the population, migration to urban areas, and the lack of jobs. Small, jobgenerating businesses are not growing due to a lack of access to finance and poor infrastructure. There is also an uneven distribution of the rural population, which ultimately 
influences social and economic development and quality of life. In recent decades, there have been significant changes in the specifics of rural areas, for example, in terms of demographic change, core occupations, and moral values.

According to Eurostat data, over $53.4 \%$ of the total population in our country is registered as living in rural areas, in 2018; this means 10,436,306 people. The total population of our country is 19.53 million people. According to available data, almost $11 \%$ of all inhabitants of predominantly rural European areas are from Romania, while predominantly rural regions occupy $67.8 \%$ of Romania and generate $36.9 \%$ of the gross added value of Romania and represent $55.9 \%$ of total employees. There are 2,854 communes that include almost 13,000 villages in Romania. Their infrastructure is somewhat developed, but it doesn't match expectations at the moment. For example, in 2018 , only $3,172,999$ people were served by the public water supply system, representing just $35.3 \%$ of the country's rural resident population.

In 2019 , only $11.3 \%$ of the population in rural areas has access to sewerage services and just $40 \%$ of households have constant access to drinking water in rural areas. In terms of water quality, more than half of it is not drinkable. Part of the rural population of Romania does indeed have the possibility to connect to the sewage water services, but they refuse to do so, motivating that construction and connectivity costs are too high. The Ministry of Public Works specified that the rate of connection of rural dwellings to public sewerage systems is $20 \%$ in 2018 .

Regarding road infrastructure, only $15 \%$ of the road network in rural areas is modernized, the rest being dirt or cobbled roads, some of which become impassable when it rains. Gas supply is reduced due to the extremely high cost of connection (thousands of euros) and underdeveloped infrastructure, in a country that possesses large gas reserves and powerful private companies in the distribution sector, companies who do not invest in expanding the gas supply network, even to areas with high demographic concentration. For regions where network expansion is not economical, one option may be to create LNG cylinder distribution systems. In rural areas, almost $80 \%$ of inhabitants were heated with wood, in often old stoves, with low combustion and low energy performance that also generated pollutant emissions into the atmosphere with effects on human health and the environment, in 2018.

Most schools in rural areas are in a state of advanced degradation, with outdoor toilets and a small number of teachers. These learning conditions are far from ideal, and along with poverty, lead to increased school dropout. Recently, the restructuring of the education network in rural areas has taken place, due to the continuing decrease of the rural population. Thus, the number of primary and secondary schools was reduced by one third. As a consequence, there has been an overcrowding of schools in urban areas, but also an increase in schooling costs in rural areas, because students sometimes have to be transported over considerable distances to schools in other towns. There are many cases of children who walk vast distances to reach schools in other villages or towns, which should be unacceptable for an E.U. Member state, in 2020. An online school system could be the cheapest solution, for certain rural areas, if investments in the communication infrastructure will be made. 
The lack of specialized schools that ensure the qualification of farmers means that almost three-quarters of them do not have the appropriate training to farm efficiently; this has a negative effect on the activity they carry out.

At the same time, medical dispensaries in rural areas are largely abandoned and closed due to a lack of doctors, which raises problems especially as the population is aging.

All these shortcomings mean Romania's rural areas do not offer the best living conditions, even in spite of allocated European funds. As a result, there is a migration of labor to nearby urban areas that require labor, or rural area citizens simply choose to other countries.

Regarding the activities carried out in rural areas, most of them are related to agriculture - agricultural farms that have undergone a series of changes in the last 30 years and especially after 2007. Regarding the used agricultural area of Romania, it was of $13,306,000$ hectares in 2010 and decreased to $12,503,000$ hectares in 2016, and the average area per farm was of 3.7 hectares, in 2016, registering an increase from 3,6 ha in 2013. In terms of the agricultural area currently in use, according to a June 2019 Eurostat Report, Romania had 3,593,830 farms in 2020; however, many of these "farms" cannot be called as such, since they use an average area of 5 hectares; in 2016, their number decreased to $3,140,770$. The last report (prepared in 2016), classified the structure of agricultural holdings according to several criteria, namely the used area, their economic power, the number of animals, and the age of the farmers or owners. In 2016, as compared to 2010 , the situation changed as follows:

- The number of small farms with 5 to 10 hectares increased from 182,440 in 2010 to 194,200 in 2016 ;

- The number of farms with 10 to 20 hectares grew from 43,610 , in 2010 , to 50,120 in 2016;

- The number of farms with 20 to 30 hectares grew from 9,730 in 2010 to 10,990 in 2016;

- The number of farms with 30 to 50 hectares decreased from 8,210 in 2010 to 7,530 in 2016;

- The number of farms with 50 to 100 hectares decreased from 7,480 in 2010 to 6,010 in 2016;

- The number of farms that had over 100 hectares decreased from 13,730 in 2010, to 12,310 in 2016 ;

There were 563,000 subsistence farms in 2019, with 20,000 less than in 2018 and 840,000 farmers worked approximately 50,000 hectares of land.

All these changes are a consequence of unequal competition that occurred particularly after 2007, in terms of prices and costs of agricultural products, on the European market. Even today, it is difficult for Romanian farms to withstand competition from E.U. farms that receive much larger subsidies and which made investments over several generations, both in equipment and mechanization, something that has not happened within Romanian farms.

When it comes to the average age of those who work the land, according to Eurostat, the situation was as follows: in 2016, there were 105,590 farmers aged below 
35, 399,850 were aged between 35 and 44; 632,780 were aged between 45 and 54, 765,450 were aged between 55 and above. The number of peasants and farmers applying for subsidies was $1,515,570$.

The age pyramid for farmers is becoming more and more important because the number of those who will retire will increase and the number of those who want to work in rural areas will be smaller and smaller, due to lower-income, as compared to the income that one can get by working in urban areas, or in other E.U. Member states.

An alternative to agricultural activities and the lack of jobs in rural areas is the development of the rural economy through ecotourism. This implies the establishment of a coherent legal framework for encouraging small-scale, rural entrepreneurship. Considering local specificity, national legislation must be changed and updated, so as to allow the consumption of household products within the ecotourism chain.

Regarding organic farming, there were over 9,000 certified producers for organic products and the land areas cultivated by them are growing.

We believe that rural development must be designed and funded on a national level, with poverty reduction as its main goal. Al programs should also support the creation of new jobs and the increase of social inclusion. However, activities in rural areas present many difficulties, primarily the large percent of the population employed in agriculture, as well as a small contribution to GDP. All these factors generate a trade deficit when it comes to processed agricultural products.

\section{National Rural Development Program 2014-2020}

During 2014 - 2020, non-reimbursable funds are granted by the E.U. Through the National Rural Development Program; this program supports the economic and social development of rural areas across the country. The Partnership Agreement with the European Union ensures convergence with the Europe 2020 strategy. The Partnership Agreement covers 5 challenges: competitiveness, people and society, infrastructure, resources, administration, and governance. Only three rural development challenges are fully addressed within the NRDP.

The NRDP 2014-2020 strategy aims to achieve its objectives through viable projects while considering the progress already made during the 2007-2013 period.

The general objective of the 2007-2013 NRDP was the increase of the competitiveness in agriculture and forestry, by improving the general performance of the processing and marketing units for these products. The idea was to achieve these objectives through better use of human resources and production factors as well as the development of the rural economy. The Program also focused on promoting equality opportunities, the general improvement of the economic environment, and the rural area, by directly supporting the sustainable management of natural resources and improving the quality of life in these rural areas. The absorption rate was good, with 6.83 billion euros being absorbed, out of the available 8.1 billion. This meant the effective absorption rate was of over $84 \%$. The money was used to finance public investments made by local authorities in rural infrastructure, as well as investments for the benefit of farmers and other entrepreneurs in villages. 
Regarding the CAP, the financing for the $2014-2020$ period increased by $27 \%$, as compared to $2007-2013$, so the CAP will receive 17.5 billion euros, as compared to 13.8 billion euros in the previous period.

Since the CAP consists of two pillars - direct payments and rural development, the amounts received evolved as follows: direct payments to farmers increased by $47.5 \%$, to 10.3 billion euros in 2014-2020, as compared to 5.6 billion during $2007-2013$, while rural development funds decreased by $13.5 \%$, from 8.2 billion euros in 2007-2013 to 7.1 billion euros in 2014-2020. This decrease was considered adequate since rural development could also be funded from other sources.

The total budget of the NRDP for 2014-2020 is 7.1 billion euros, to which Romania added 1.3 billion Euros as national funding. The absorption rate of European funds from the NRDP at the beginning of 2020 was $52.28 \%$, meaning approximately 4.25 billion euros.

By analyzing the main challenges and commitments in the Romanian Partnership Agreement regarding the financing conducted through the NRDP, we conclude that the agricultural sector and the rural economy still have under-exploited growth potential and that it is necessary to transform and modify rural villages threatened by chronic poverty.

In order to support the competitiveness of rural activities, investments in farms are critical; they should include the purchasing of modern equipment for processing agricultural products, including seasonal fruits and vegetables, but also investments in the building of warehouses for storing primary agricultural products in optimal conditions, and in transport equipment and infrastructure, so as to better connect farmers with urban areas and grant them additional export possibilities.

The merging of small and medium-sized lands should also be encouraged, through an appropriate legislative framework, for the purpose of modernizing farms through European-funded programs. Such measures ensure a balance between food consumption and high value-added food requested by the internal and external market, due to increased productivity and competitiveness.

Promoting employment and social inclusion refers to the employment of the population with a low level of training in agricultural and non-agricultural activities. Achieving this goal requires higher farming skills, improved knowledge of new technologies for agricultural crops, and thorough knowledge of climate change and sustainable development. Knowledge of climate change and sustainable development should be included in high school textbooks so that all students have access to these critical concepts. A major and topical challenge for rural areas is the influence of sustainable development and climate change because it directly affects the quality of life.

It is also essential to support the transition to a low-carbon economy in all sectors, in line with NRDP requirements. These established measures provide support for all rural economic sectors, provide assistance for investments in organic farming and energy efficiency, but also support the transition towards a low-carbon economy. Another action is to support increased energy efficiency by reducing primary energy consumption for agricultural work and food processing. For this purpose, the use of renewable resources is recommended, as well as better waste and residue management. 
Promoting adaptation to climate change and preventing risk management must include measures to restore, preserve, and enrich ecosystems that are dependent on agriculture and forestry. Other measures to support rural areas should refer to the rational use of water in agriculture, the conservation of soil carbon reserves through proper land management, and maintaining the diversity of flora and fauna, where the land is not arable.

The Europe 2020 strategy envisages increasing energy efficiency by $20 \%$, in order to mitigate the effects of climate change by investing in energy-efficient machinery, reducing energy consumption from greenhouse gas emissions, and using clean energy.

\section{Conclusions}

Not all investment projects are imposed by the European Union, but the Member States can choose the projects they want to undertake, depending on their specific needs.

The territories of rural areas that are affected by climate change (for example, prolonged drought or heavy rainfalls), must be supported, as climate change destroys arable land and depopulates villages and towns located near riverbeds. We believe that in order to adapt to climate change, investments are needed inefficient projects, drawn up by specialists; however, these projects must also include the knowledge the inhabitants of rural areas possess.

The Rural Development Strategy 2014-2020 aims for the reduction of greenhouse gases from agriculture, and the increasing of forested areas, as massive deforestation has already occurred. In addition, it proposes the forestation of areas with eroded soils, where other agricultural activities cannot be practiced.

The future Strategic Plan for rural development, for 2021-2027, must reduce the chronic poverty of rural areas by eliminating the income gap as compared to urban areas. Rural areas need to produce more agricultural food products, both for domestic consumption and for export. By rebuilding the existing infrastructure, agriculture must become modern, efficient, and in line with European demographic trends.

Sustainable development and climate change must become major targets for funding from European rural development funds.

We believe these are the reasons for which a large part of the population in rural areas in Romania abandons their lands and often their homes, choosing to migrate to Western countries, seeking to fulfill their European dream - a better and safer life.

\section{References}

Baum, S., Weingarten P., (2004). „Typisierung ländlicher Räume in Mittel-und Osteuropa“, Europa Regional, p.149-150

Bold, I., Buciuman, E., Drăghici, M. (2003). "Rural areas. Definition, organization, development", Editura Mitriton, Timişoara

Bucur, S. I. (2015). "Characteristics and Temporal Gaps of the Rural Space", Institute of Agricultural Economics, Romanian Academy 
Dax Th., Machold, I., (2007). „Forderung der landwirtschaftlich benachteiligten Gebiete in den neuen Mitgliedstaaten der EU, Ländlicher Raum-Online Fachzeitschrift des Bundesministerium für Land-und Forstwirtschaft, Umwelt und Wasserwirtschaft"

Gallardo-Cobos, R., (2010). "Rural Development in the European Union: the concept and the policy" Mihalache F., Croitoru A., (2011). „The Romanian Rural Area: Evolutions and Involutions. Social change and entrepreneurship", Editura Expert, Bucharest

Moseley, M., (2003). „Rural Development: Principles and Practice”, Sage Publications, London

Otiman, I.P. (1997). "Rural Development in Romania", Agroprint Publishing House, Timişoara

Popescu M., Popescu C., Per E., Csosz I., (2018). „Rural area and rural development. Definition and features”, Scientific Works, Series I, vol.20, nr.2, pp. 88-93

Rusali, M.A., (2013). „Rural Economic Development in Romania. Concepts and evaluations”. Editura Digital Data, Cluj Napoca

Steiner, M., (2003). „Ländliche Regionen -gibt”s die?“ EINIGE Anmerkungen und Strategien, nr.4

Velcea I., (2014). „Functionalities and Development Strategies”, Geographica Timisiensis, vol.XXIII, nr. 1, p.17-31

https://academiaromana.ro/SARS-CoV-2/doc/d17-Sectorul agricol mediul rural.pdf

https://gov.ro/fisiere/stiri fisiere/Viziunea Guvernului Rom\%C3\%A2niei pentru dezvoltarea clasei de mijloc la sate.pdf

https://www.agroinfo.ro/economic/raport-oficial-iunie-2019-structura-fermelor-din-romania

https:/lec.europa.eu/info/sites/info/files/food-farming-fisheries/farming/documents/agri-statisticalfactsheet-ro en.pdf

https://sgg.gov.ro/new/wp-content/uploads/2016/04/PSI-MADR-RO.pdf

https://enrd.ec.europa.eu/country/romania en

https://ec.europa.eu/info/food-farming-fisheries/key-policies/common-agricultural-policy/rural-

development/country en

https:/lec.europa.eu/info/sites/info/files/file_import/2019-european-semester-country-report-

romania en.pdf

https://www.fi-compass.eu/esif/eafrd

https://portal.afir.info/informatii generale pndr dezvoltare rurala feadr

http://www.institutdelors.eu/wp-content/uploads/2018/01/ruraldevelopmentreformmantinoneoct10.pdf

http://www.scielo.org.co/scielo.php?script=sci arttext\&pid=S0120-99652010000300014

http://www.ipe.ro/RePEc/iag/iag_pdf/AERD1502_223-235.pdf

https://geografie.uvt.ro/wp-content/uploads/2015/06/2-VELCEA-1.pdf

http://www.digitaldata.ro/wp-content/uploads/MAR1

Dezvoltarea economica a ruralului in Romania site.pdf

http://www.fao.org/3/ca6392en/ca6392en.pdf 